\title{
The impact of disease-related immobilization on thigh muscle mass and strength in older hospitalized patients
}

\author{
Nikola Rommersbach', Rainer Wirth', Gero Lueg ${ }^{1}$, Christiane Klimek', Mirja Schnatmann², Dieter Liermann², \\ Gregor Janssen ${ }^{1}$, Manfred James Müller ${ }^{3}$ and Maryam Pourhassan ${ }^{1 *}$ (I)
}

\begin{abstract}
Background: We assessed the quantitative changes in muscle mass and strength during 2 weeks of hospitalization in immobile and mobile acutely ill hospitalized older adults.

Methods: Forty-one patients ( $82.4 \pm 6.6$ years, $73.0 \%$ females) participated in this prospective longitudinal observational study. Mobility status was defined according to walking ability as described in the Barthel-Index. Functional status, including handgrip strength and isometric knee-extension strength, and mid-thigh magnetic resonance imaging (MRI) measurements of cross-sectional area (CSA) were conducted on admission and at discharge.
\end{abstract}

Results: Twenty-two participants (54\%) were immobile and 19 (46\%) mobile. In all, 54.0 and $12.0 \%$ were at risk of malnutrition and malnourished, respectively. The median time between baseline and follow-up for MRI scans were 13 days in mobile and immobile participants $(P=0.072)$. Mid-thigh muscle and subcutaneous fat CSA significantly decreased by $3.9 \mathrm{~cm}^{2}(5.0 \%, P=0.002)$ and $5.3 \mathrm{~cm}^{2}(5.7 \%, P=0.036)$ during hospitalization whereas intermuscular fat remained unchanged in immobile subjects. No significant changes were observed in mobile patients. In a regression analysis, mobility was the major independent risk factor for changes in mid-thigh muscle CSA as a percentage of initial muscle area $(P=0.022)$ whereas other variables such as age $(P=0.584)$, BMI $(P=0.879)$, nutritional status $(P=0.835)$ and inflammation $(P=0.291)$ were not associated with muscle mass changes. There was a significant decrease in isometric knee extension strength $(P=0.002)$ and no change in handgrip strength $(P=0.167)$ in immobile patients whereas both parameters increased significantly over time in mobile patients ( $P=0.048$ and $P=0.012$, respectively).

Conclusions: Two weeks of disease-related immobilization result in a significant loss of thigh muscle mass and muscle strength in older patients with impaired mobility. Concomitantly, there was a significant reduction of subcutaneous adipose tissue in immobile older hospitalized patients whereas no changes were observed in intermuscular fat among these patients. These data highlight the importance of mobility support in maintaining muscle mass and function in older hospitalized patients.

Keywords: Muscle mass, Muscle strength, Adipose tissue, Intermuscular fat, Immobilization

\footnotetext{
* Correspondence: mpourhassan1918@gmail.com

'Department of Geriatric Medicine, Marien Hospital Herne, Ruhr-Universität

Bochum, Hölkeskampring 40, 44625 Herne, Germany

Full list of author information is available at the end of the article
}

(c) The Author(s). 2020 Open Access This article is licensed under a Creative Commons Attribution 4.0 International License, which permits use, sharing, adaptation, distribution and reproduction in any medium or format, as long as you give appropriate credit to the original author(s) and the source, provide a link to the Creative Commons licence, and indicate if changes were made. The images or other third party material in this article are included in the article's Creative Commons. licence, unless indicated otherwise in a credit line to the material. If material is not included in the article's Creative Commons licence and your intended use is not permitted by statutory regulation or exceeds the permitted use, you will need to obtain permission directly from the copyright holder. To view a copy of this licence, visit http://creativecommons.org/licenses/by/4.0/. The Creative Commons Public Domain Dedication waiver (http://creativecommons.org/publicdomain/zero/1.0/) applies to the data made available in this article, unless otherwise stated in a credit line to the data. 


\section{Background}

Alterations in body composition with advancing age have important implications for functional status, health and survival. The progressive loss of muscle mass, muscle strength and physical performance is a part of the aging process. It affects individuals from almost the age 50 years with an annual rate of decline in muscle mass and muscle strength by 1 and $3 \%$, respectively [1-3]. However, the magnitude and severity of decline in muscle mass and muscle strength may depend on health compromising behaviors such as physical inactivity and nutritional difficulties [4, 5] and may further deteriorate by disease and disease-related immobilization [6]. The term sarcopenia was employed to describe patients with compromised muscle mass and function and define clinically relevant threshold values for muscle mass, strength and function [6].

The presence of sarcopenia is associated with adverse health outcomes such as physical disability, falls, frailty, hospital admissions and mortality [3, 7]. In our recent study [8] among 198 older hospitalized patients (mean age $82.8 \pm 5.9$ years), after adjustment for potential confounders such as age and gender, sarcopenia was associated with increased 1-year mortality among patients with limited mobility prior to admission $(n=138$, hazard ratio, HR: 2.52, 95\% CI: $1.17-5.44)$ and at time of discharge ( $n=162$, HR: 1.93 , 95\% CI: 0.67-3.22). In another prospective cohort study in persons aged over 80 years living in the community, Landi et al. [9] reported that patients with sarcopenia had a higher risk of death during the 10-year follow-up than those without sarcopenia $(\mathrm{HR}=2.15$; 95\% CI: $1.02-4.54)$. In addition to physiological age-related causes of sarcopenia, reduced mobility, low food intake and inflammation also play an important role $[10,11]$. Indeed, the interplay between acute diseases and factors such as immobility and malnutrition, all prevalent among older adults, may superimpose and accelerate the process of muscle loss in this population $[12,13]$.

A variety of conditions, such as falls and fractures, surgical interventions, acute diseases and hospitalization lead to immobilization, muscle disuse and functional decline $[11,14]$, which may further aggravate the loss of muscle mass and muscle strength $[11,15,16]$. Previous bed rest studies reported that healthy older adults lost approximately $4-6 \%$ of total lean leg mass following seven to ten days of immobility $[17,18]$. However, these studies investigated changes in lean mass among healthy older adults using experimental models of immobilization. Still, very little is known about the consequences of disease-related immobilization on body composition and muscle among immobile frail older hospitalized patients. Recently, Kouw et al. [19] indicated that 1 week of hospitalization following elective hip surgery resulted in substantial loss in thigh muscle mass of the unaffected leg by $4.2 \%$, as measured by computed tomography, in older hospitalized patients. However, it is of great importance to determine the effect of immobility during hospitalization not only on muscle mass, but also on subcutaneous fat and its role in metabolic changes [20] and on intermuscular fat as a potential contributor to decreasing muscle strength and muscle quality in older individuals [21-23]. Beyond muscle mass, adipose tissue (e.g. intermuscular fat) has also significant role in mobility limitation in older adults and may influence muscle health and quality [24]. Results of previous studies among older individuals demonstrated a close association between adipose tissue and muscle mass function and mobility [25, 26]. Therefore, measurement of fat mass should be also considered in preserving muscle strength and muscle quality in old age. In addition, it is essential to investigate the impact of muscle mass loss on changes in muscle strength as the most relevant parameter for functional limitation. To the best of our knowledge, no studies have specifically examined such associations among acutely ill immobile older hospitalized patients up to now.

Magnetic resonance imaging (MRI) is the gold standard for assessment of body composition, although its application is limited due to time-consuming assessment of whole-body tissue volumes and high costs [27-29]. Therefore, several studies have suggested to estimate muscle volumes from a single-slice section at mid-thigh [29-31], since lower limb power has been considered as a critical factor for mobility in older adults [32]. With the assumption that thigh muscles correspond to spheroids, any change in cross-sectional area is proportional to the respective change in volume. The aim of this study was to examine the impact of 2-weeks diseaserelated immobilization on muscle mass and fat mass among acutely ill older hospitalized patients. Accordingly, we assessed the quantitative changes in muscle, subcutaneous and intermuscular fat cross-sectional area using a single-slice MRI at mid-thigh and compared the data with a healthier and mobile group of older patients during hospitalization as a reference group.

\section{Methods}

This prospective observational study was performed at the geriatric department of our university hospital. A detailed description of the methods has been reported elsewhere [33]. Mobility status was evaluated according to walking ability as described by the respective item of the Barthel-Index (BI) [34] and patients were grouped into two categories as mobile group (walking ability 
score of 15 or 10) and immobile group (walking ability score of 5 or 0 ).

It is worth noting that mobile and immobile patients were selected from the geriatric day clinic and the geriatric hospital department, respectively. Geriatric day clinic is a facility in between ambulatory and in-patient treatment, i.e. patients stay for 7-8 h every day for several days and get their diagnostic procedures and treatment. The remaining time they stay at home, which implies they are more or less mobile and able to take care for themselves. Indeed, patients from the geriatric day clinic had better functional and nutritional status compared to those from the geriatric hospital department. In general, the patients who are admitted to the geriatric hospital department are really ill and frail and sometime stay even more than 16 days in hospital based on their clinical situation.

The inclusion criteria for participation of both groups were patients of 65 years or older who were expected to be hospitalized for at least 14 days, ability to cooperate and written informed consent. Exclusion criteria were immobility longer than 3 weeks before recruitment, leg amputation, pacemaker implants and severe disturbance of fluid status. Barthel-Index, measurement of muscle strength, body weight and mid-thigh MRI measurements were conducted within $24 \mathrm{~h}$ after hospital admission (baseline) and before discharge (follow-up). In addition, geriatric assessment was performed and C-reactive Protein (CRP) was analyzed according to standard clinical procedures at hospital admission. The study protocol had been approved by the ethical committee of RuhrUniversity Bochum (17-6048, approved on 08.08.17).

Self-caring ability and functional status were determined using Barthel-Index (BI) [34], the FRAIL scale [35] and the SARC-F questionnaire [36]. The number and severity of medical comorbidities were classified with the Charlson Comorbidity Index (CCI) [37].

Nutritional status was evaluated using the Mini Nutritional Assessment Short Form (MNA-SF) [38] and food intake was determined using the semi-quantitative plate diagram method [39].

Body weight was assessed in light clothing with an accuracy of $0.1 \mathrm{~kg}$ and height was measured to the nearest $0.5 \mathrm{~cm}$ with a stadiometer during hospitalization. The degree of unintentional weight loss prior to admission was obtained either by interviewing the patients, if competent, or asking their proxy, where necessary.

Irrespective of mobility status, similar nutrition was provided to all patients except oral nutritional supplements which were only provided for malnourished patients. Physical therapy for at least 30 min twice a day was offered to all patients as a routine rehabilitation program. However, immobile patients who were more or less bedridden participated less. Furthermore, all patients had an individualized training program according to the deficiencies in activities of daily living.

The protocol described by Gandevia [40] and a Jamar dynamometer were used to assess isometric knee extension strength and hand grip strength (HGS) respectively. Knee strength was measured while sitting on a chair with a strap around the distal leg (Fig. 1a). The best of three attempts was recorded.

MRI scans were performed with a Siemens Magnetom Sonata, 1,5 Tesla (Siemens Medical Solutions, Erlangen, Germany) at a reproducible position of mid-thigh to quantify muscle, subcutaneous and intermuscular fat cross-sectional area (CSA). The details of the procedure including the segmentation are described elsewhere [33].

\section{Statistical analysis}

The statistical analysis was performed using SPSS statistical software (SPSS Statistics for Windows, IBM Corp, Version 24.0, Armonk, NY, USA). Continuous variables are expressed by their means and standard deviations (SDs) or median values with interquartile ranges (IQR), as appropriate. Categorical variables are expressed as $n$ (\%). Differences between immobile and mobile groups were analyzed by using paired samples $t$ test for normally distributed values. The magnitude of changes at follow-up between groups were analyzed by using an unpaired $t$ test in normally distributed variables and the Mann-Whitney $U$ test for continuous variables with non-normal distribution. Chi square test was used to compare categorical variables. A stepwise multiple regression analysis was used to examine the impact of risk factors such as mobility status, age, BMI, malnutrition and inflammation (as independent variables) on changes in mid-thigh muscle CSA as a percentage of initial muscle area as (dependent variable). $P<0.05$ was determined as the limit of significance.

\section{Results}

\section{Subject characteristics}

Baseline characteristics of study participants stratified by mobility status are summarized in Table 1 . Of 41 patients with a mean age of $82.4 \pm 6.6$ years $(73.0 \%$ females), 22 (54\%) were immobile (64.0\% females) and 19 (46\%) were mobile ( $84.0 \%$ females). In total study population, 34.0 and $54.0 \%$ had normal nutritional status or a risk of malnutrition, respectively whereas $12.0 \%$ were malnourished according to MNA-SF. Major reasons for hospitalization were $59.0 \%$ musculoskeletal diseases including fractures (e.g. vertebral, femoral and pelvic fractures), $15.0 \%$ gait disorders and $26.0 \%$ various general diseases such as heart failure, stroke and infectious diseases. Twelve of the immobile patients underwent surgery prior to the admission to the geriatric ward. In addition, the reasons for hospitalization in the 
a)

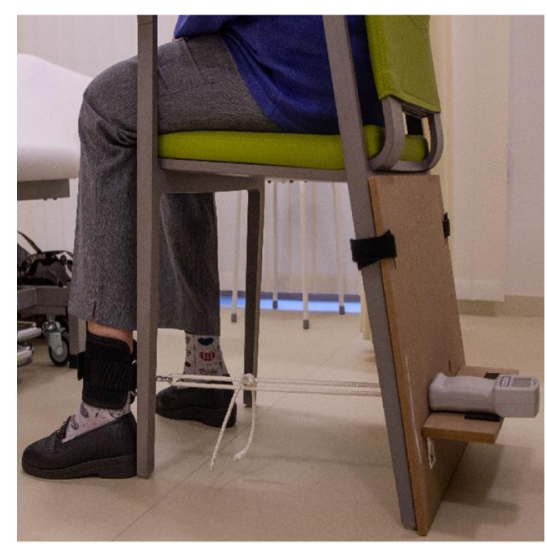

b)

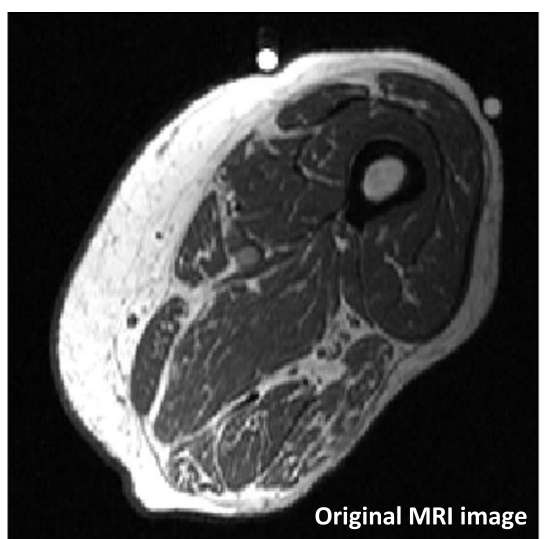

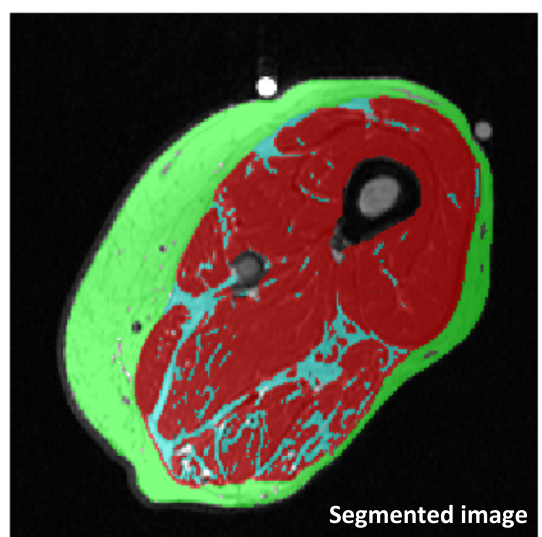

Segmented image

Fig. 1 a Maximal isometric knee extension strength measurement and $\mathbf{b}$ A sample of single-slice mid-thigh MRI image of a 68-year-old female, mobile patient before and after segmentation. Structures in red: muscle, green: subcutaneous fat, blue: intermuscular fat

Table 1 Characteristic of study population at baseline (TO) stratified by mobility status

\begin{tabular}{|c|c|c|c|}
\hline & All $(n=41)$ & Immobile group $(n=22 ; 54 \%)$ & Mobile group $(n=19 ; 46 \%)$ \\
\hline Female & $30(73.0)$ & $14(64.0)$ & $16(84.0)$ \\
\hline Male & $11(27.0)$ & $8(36.0)$ & $3(16.0)$ \\
\hline Age (y) & $82.4 \pm 6.6$ & $82.5 \pm 6.5$ & $82.2 \pm 6.8$ \\
\hline Height (m) & $1.61 \pm 0.1$ & $1.64 \pm 0.1$ & $1.58 \pm 0.1^{*}$ \\
\hline $\mathrm{BMI}\left(\mathrm{kg} / \mathrm{m}^{2}\right)$ & $28.4 \pm 6.4$ & $26.3 \pm 4.8$ & $30.7 \pm 7.3^{*}$ \\
\hline Weight loss in 6 months (kg) & $2.2 \pm 3.1$ & $2.6 \pm 3.0$ & $1.7 \pm 3.3$ \\
\hline CRP (mg/dl) & $2.5 \pm 5.5$ & $4.1 \pm 7.1$ & $0.6 \pm 1.0^{*}$ \\
\hline MNA-SF score, Median (IQR) & $10(8-12)$ & $9(7-10)$ & $12(11-13)^{* * *}$ \\
\hline Normal nutritional status (n; \%) & $14(34.0)$ & $1(4.0)$ & $13(68.0)$ \\
\hline At risk of malnutrition (n; \%) & $22(54.0)$ & $16(73.0)$ & $6(32.0)$ \\
\hline Malnourished (n; \%) & $5(12.0)$ & $5(23.0)$ & $0(0.0)$ \\
\hline Barthel-Index on admission, Median (IQR) & $55(40-67)$ & $40(35-51)$ & $70(60-80)^{* * *}$ \\
\hline Frail Simple scale score, Median (IQR) & $3(2-3)$ & $3(2-3)$ & $3(2-3)$ \\
\hline SARC-F scores, Median (IQR) & $6(4-7)$ & $7(5-8)$ & $5(2-6)^{* *}$ \\
\hline CCl score, Median (IQR) & $2(1-3)$ & $2(1-3)$ & $2(1-2)$ \\
\hline Handgrip strength $(\mathrm{kg})$ & $19.8 \pm 8.3$ & $20.1 \pm 8.3$ & $19.4 \pm 8.5$ \\
\hline Isometric knee extension strength (kg) & $16.6 \pm 6.7$ & $16.4 \pm 6.9$ & $17.0 \pm 6.8$ \\
\hline \multicolumn{4}{|l|}{ Mid-thigh MRI cross sectional area $\left(\mathrm{cm}^{2}\right)$} \\
\hline Muscle area & $81.2 \pm 18.2$ & $78.7 \pm 17.3$ & $84.0 \pm 19.3$ \\
\hline Subcutaneous fat area & $89.4 \pm 53.2$ & $80.0 \pm 44.4$ & $100.3 \pm 61.3$ \\
\hline Intermuscular fat area & $18.1 \pm 9.5$ & $17.1 \pm 9.0$ & $19.2 \pm 10.3$ \\
\hline
\end{tabular}

CRP C-reactive protein, MNA-SF Mini Nutritional Assessment Short Form (normal nutritional status 12-14 points, at risk of malnutrition 8-11 points and malnourished 0-7 points); Frail Simple scale (not frail with score 0, pre-frail with scores of 1-2 and frail with 3-5); SARC-F scores (high risk of sarcopenia with score $\geq 4$ ); CCI Charlson Comorbidity Index, MRI Magnetic Resonance Imaging. Values are given as mean \pm SD, number (\%) or median (IQR, interquartile range). There were no significant differences in gender distribution between the mobile and immobile groups $(P=0.138) .{ }^{*} P<0.05,{ }^{* *} P<0.01,{ }^{* * *} P<0.001$, Difference between immobile and mobile patients (unpaired $\mathrm{t}$ test) 
immobile group were similar to the entire population with the corresponding values of 57.0, 14.0 and $29.0 \%$, respectively.

The patients in the immobile group were taller $(P=0.037)$, had lower BMI $(P=0.032)$ and Barthel-Index $(P<0.001)$ and showed a higher prevalence of poor nutritional status $(P<0.001)$ at baseline than the mobile group. In addition, frailty was present in immobile and mobile patients $(P=0.087)$ and both groups had probable sarcopenia according to SARC-F with higher median value in immobile patients $(P=0.004)$. At baseline, the mean CRP level was $2.5 \pm 5.5 \mathrm{mg} / \mathrm{dl}$ in total population indicating moderate inflammation. The mean CRP level was significantly higher in immobile $(4.1 \pm$ $7.1 \mathrm{mg} / \mathrm{dl})$ than in mobile patients $(0.6 \pm 1.0 \mathrm{mg} / \mathrm{dl}$; $P=0.030$ ). Furthermore, immobile and mobile groups did not significantly differ at baseline for handgrip strength, knee extension strength and mid-thigh CSA (Table 1).

No statistically significant differences either in average length of stay $(P=0.208)$ or in time between baseline and follow-up MRI scans $(P=0.072)$ between mobile and immobile patients were observed. The median time from baseline to follow-up for MRI scan was 13 days in both mobile (IQR: 12-15) and immobile groups (IQR: 10-14).

\section{Comparison of CSA of MRI}

Detailed results for mid-thigh MRI-CSA stratified by mobility status at baseline and follow-up and respective changes during hospitalization are shown in Table 2 and Fig. 2. At baseline, no significant differences in mean mid-thigh CSA of muscle, subcutaneous and intermuscular fat between the immobile and mobile group were found. By contrast, mean mid-thigh muscle CSA significantly decreased by $3.9 \mathrm{~cm}^{2}(5.0 \%)$ during hospital stay in immobile patients $(P=0.002)$ and remained unchanged in mobile patients $(P=0.717)$. In addition, changes in mid-thigh muscle CSA per day was significantly higher in immobile patients compared to the mobile group $\left(-0.3 \mathrm{~cm}^{2}\right.$ vs. $+0.1 \mathrm{~cm}^{2} ; P=0.013$, respectively; Table 2). In a stepwise regression analysis, mobility was the major independent risk factor for changes in mid-thigh muscle CSA as a percentage of initial muscle area $(P=0.022)$ whereas other variables such as age $(P=0.584)$, BMI $(P=0.879)$, MNA-SF $(P=0.835)$ and CRP level $(P=0.291)$ did not show any impact on muscle mass changes.

Moreover, evaluation of mid-thigh CSA of subcutaneous fat identified a statistically significant decline of 5.3 $\mathrm{cm}^{2}(5.7 \%)$ in immobile patients only $(P=0.036)$. Concomitantly, absolute mid-thigh CSA of intermuscular fat and body weight remained unchanged over time in both groups (Table 2). Furthermore, Barthel-Index substantially improved during hospitalization in immobile and mobile groups (both $P<0.001$ ) with significantly more improvement in immobile patients $(P=0.05$, Table 2$)$.

There was a significant decline of $12 \%$ in isometric knee extension strength (T0: $16.6 \mathrm{~kg}, \mathrm{~T} 1: 14.5 \mathrm{~kg}$; $P=0.002)$ and nearly no change in handgrip strength (T0: $20.1 \mathrm{~kg}, \quad \mathrm{~T} 1: 19.1 \mathrm{~kg} ; \quad P=0.167$ ) in immobile patients during hospitalization whereas knee extension (T0: $16.9 \mathrm{~kg}, \mathrm{~T} 1: 18.1 \mathrm{~kg} ; P=0.048$ ) and handgrip (T0: $19.4 \mathrm{~kg}, \quad \mathrm{~T} 1: 20.8 \mathrm{~kg} ; P=0.012$ ) strength increased significantly over time in mobile patients. Further, no significant differences in the amount of food intake were observed between mobile and immobile groups $(P=0.196)$.

\section{Discussion}

The major finding of the present study is that almost 2 weeks of disease-related immobility result in significant thigh muscle mass loss of $5.0 \%$ in a group of immobile older patients admitted to an acute care geriatric unit, while such an effect was not seen among mobile older patients. Notably, this substantial reduction occurred

Table 2 Comparison of mean mid-thigh MRI cross sectional area (cm2), body weight and Barthel-Index of study population stratified by mobility status at baseline (T0) and follow-up (T1)

\begin{tabular}{|c|c|c|c|c|c|c|c|c|}
\hline \multirow[b]{2}{*}{ Mid-thigh CSA $\left(\mathrm{cm}^{2}\right)$} & \multicolumn{4}{|c|}{ Immobile group $(n=22)$} & \multicolumn{4}{|c|}{ Mobile group $(n=19)$} \\
\hline & T0 & T1 & $\Delta \mathrm{T} 1-\mathrm{T0}$ & $\Delta$ /day & TO & T1 & $\Delta \mathrm{T} 1-\mathrm{T} 0$ & $\Delta /$ day \\
\hline Muscle area & $78.7 \pm 17.3$ & $74.8 \pm 17.9$ & $-3.9 \pm 5.0^{* *} \dagger$ & $-0.3 \pm 0.4+\dagger$ & $84.0 \pm 19.3$ & $84.5 \pm 20.6$ & $0.5 \pm 5.6$ & $0.1 \pm 0.5$ \\
\hline Subcutaneous fat area & $80.0 \pm 44.4$ & $74.7 \pm 40.0$ & $-5.3 \pm 11.1^{*}$ & $-0.5 \pm 1.0$ & $100.3 \pm 61.3$ & $97.9 \pm 56.9$ & $-2.4 \pm 18.2$ & $-0.1 \pm 1.3$ \\
\hline Intermuscular fat area & $17.1 \pm 9.0$ & $16.0 \pm 8.9$ & $-1.1 \pm 2.9$ & $-0.1 \pm 0.2$ & $19.2 \pm 10.3$ & $19.4 \pm 12.1$ & $0.2 \pm 3.5$ & $0.0 \pm 0.3$ \\
\hline Body weight (kg) & $70.9 \pm 14.4$ & $70.1 \pm 14.9$ & $-0.8 \pm 2.5$ & $-0.05 \pm 0.2$ & $77.2 \pm 19.0$ & $75.8 \pm 19.0$ & $-1.5 \pm 7.1$ & $-0.1 \pm 0.5$ \\
\hline Barthel-Index & $42.3 \pm 11.4$ & $61.8 \pm 16.8$ & $19.5 \pm 13.0^{* * *} \dagger$ & $1.4 \pm 1.0$ & $68.7 \pm 11.9$ & $81.3 \pm 8.8$ & $12.6 \pm 8.7^{* * *}$ & $0.9 \pm 0.6$ \\
\hline
\end{tabular}

All values are means \pm SDs. No significant group difference in time between baseline and follow-up of MRI scan was observed $(P=0.072)$. The median time of follow-up for MRI scan was 13 days in both mobile (IQR: 12-15) and immobile groups (IQR: 10-14)

CSA cross sectional area, MRI Magnetic Resonance Imaging, $\triangle T 1-T 0$ difference between baseline and follow-up, $\Delta /$ day change per day

${ }^{*} P<0.05,{ }^{* *} P<0.01,{ }^{* * *} P<0.001$ Difference between $\mathrm{T} 0$ and $\mathrm{T} 1$ within group (paired t test)

$+P<0.05$ Difference in $\Delta \mathrm{T} 1-\mathrm{T} 0$ between groups (unpaired $\mathrm{t}$ test)

$t+P<0.05$ Difference in $\Delta /$ day between groups (unpaired $\mathrm{t}$ test) 


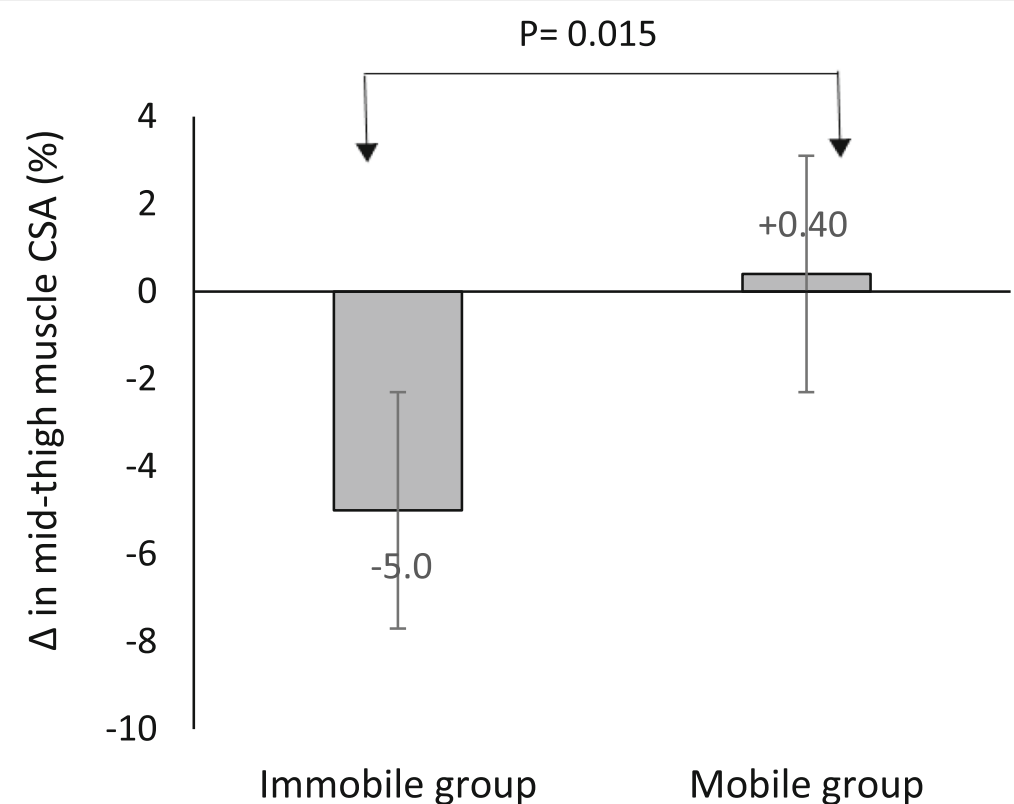

Fig. 2 Comparison of changes in mid-thigh muscle cross-sectional area (CSA) as a percentage of initial muscle area between immobile $(n=22)$ and mobile patients ( $n=19$; unpaired t test) after 13 days of hospitalization

despite providing the medical support and training therapy offered in geriatric units. It can only be speculated how much muscle mass and strength would have been lost without this support. The detrimental impact of bed rest on muscle mass and strength has been already reported in previous experimental models of immobilization in healthy older adults. Studies using muscle mass disuse model have shown approximately 2-6\% reduction of leg muscle mass following 5 to 14 days among this population [16, 18, 41].

However, only few published studies have investigated the actual muscle mass loss in a clinical setting. Namely, the effect of immobilization on muscle mass remains to be elucidated in acutely ill older hospitalized patients who are likely to experience a more pronounced loss of muscle mass due to their condition. Hospitalization is commonly accompanied by enforced bedrest or poor mobility induced by pain, surgical trauma, infections and mental stress, leading to changes in food intake and skeletal muscle catabolism [19, 42, 43]. Consequently, we hypothesized that even a short period of hospital stay may result in a significant loss of muscle mass and strength in patients with severe mobility limitation. In a recent observation study in older patients undergoing elective hip replacement, Kouw et al. [19] reported a significant loss of thigh muscle CSA by $4.2 \% \pm 1.1 \%(0.6 \%$ per day) using CT scan during one-week hospitalization. Our findings were similar, although our patients were older and experienced 5.0\% reduction in MRI-derived mid-thigh muscle CSA during the course of a 13-day hospitalization period ( $0.4 \%$ per day). Notably, disease- related immobilization in our cohort started up to 3 weeks before admission to our department and thus before the first MRI scan. In line with our findings and the aforementioned study, we assume that within the first days of immobilization, the rate of muscle mass loss may be even higher than in our study and may decrease over time, due to metabolic adaptations.

In another prospective study of 63 critically ill patients (mean age 54.7 years), Puthucheary et al. [44] has indicated the significant decline in the ultrasoundderived rectus femoris CSA by $17.7 \%$ at day 10 of hospitalization. However, the changes in muscle mass were greater compared to our findings. Although, direct comparison is difficult since that study used a different method for assessing muscle mass and patients were younger and suffered from multi-organ failure. Nevertheless, it has to be noted that in that study reduction of muscle mass was more severe among those with multi-organ failure compared with single organ failure. Indeed, despite the fact that immobilization is a factor in development of muscle atrophy, patients with multi-organ failure may develop more muscle mass loss as a result of greater metabolic changes $[45,46]$ and other deleterious factors associated with severe disease, rather than immobility alone [44]. In the present study, despite the similar midthigh muscle CSA in both mobile and immobile older adults at baseline, the MRI scans, which provide a very sensitive and accurate measurement, clearly indicated the substantial decline in muscle mass only in immobile older patients during hospitalization. Moreover, 
the majority of our immobile patients were frail, probably sarcopenic and were at risk of malnutrition or malnourished at the time of admission. Therefore, the combination of these factors may have affected the extent of muscle mass loss in our study [19, 42, 43].

In addition, prior researches on the morphologic changes associated with immobility in older adults have commonly concentrated on muscle mass whereas changes in subcutaneous or intermuscular fat have not received a great deal of attention. However, this knowledge is important since alterations in adipose tissue are linked with dysfunction and metabolic changes in skeletal muscle $[47,48]$. Indeed, interaction between adipose tissue and muscle mass is influenced by mobility and aging. Mobility limitation caused by aging leads to decline in muscle mass and function and alteration in body fat composition [24]. With advancing age, intermuscular adipose tissue increases [24] and subcutaneous tissue decreases [49]. These significant changes in fat composition may have a negative impact on health outcome in old age. Fatty infiltration of the skeletal muscle is a metabolically active component of muscle and affects muscle strength and muscle quality [50]. It secretes inflammatory cytokines which negatively impact muscle cell proliferation and differentiation [50]. The findings of the present study demonstrated a significant decline in mid-thigh subcutaneous fat area in immobile patients without changes in intermuscular fat. It has been previously shown that immobilization leads to increased intermuscular fat $[51,52]$. For instance, intermuscular adipose tissue of thigh increased in healthy young patients during 4 weeks of immobilization [51] and in patients with spinal cord injury [52]. However, this could not be shown in the period of 13 days of immobilization in our study. This discrepancy could be a result of differences in the study populations and in length of the follow-up period. Since the current sample included ill older adults with several risk factors such as malnutrition, frailty and severe disease, immobilization may specifically and differentially affect both adipose tissues in our population. From a metabolic point of view, our findings indicate that subcutaneous and intermuscular fat may have structural and functional differences in response to immobilization and are subject to distinct dysfunctional changes caused by disease, aging and lifestyle. Indeed, subcutaneous adipose tissue is metabolized during periods of immobilization and decreased nutritional intake and seems to be metabolically more active compared to intermuscular fat. Moreover, previous cross-sectional studies have demonstrated that a greater fat infiltration of the muscle is an independent risk factor for mobility limitations and is a potential contributor to decreasing muscle strength and muscle quality in older individuals $[1,23]$.
Our results indicate a significant decrease in isometric knee extension strength and nearly no change in handgrip strength during hospitalization of acutely immobile patients. Accordingly, it could be that even short periods of immobilization do not only influence muscle mass but may have also negative effects on muscle strength and physical functioning of lower extremity of older adults and are likely to contribute to impaired recovery, increased readmissions and a higher mortality rate after discharge [53]. Interestingly, the distinct loss of lower and upper extremity strength demonstrates that disease-related immobility has a more pronounced effect on leg muscle strength compared to hand grip strength. Therefore, muscle strength of the leg seems to be the most relevant parameter for functional decline and can reflect mobility limitation whereas upper muscle strength is more related to general body composition. Hence, measurements of leg strength should receive more priority compare to hand grip strength, especially when studying older persons.

Some limitations of the study need to be addressed. Mobility status was defined according to walking ability as described by the BI, which may be imprecise. Nevertheless, a previous study in patients with stroke [54] has demonstrated that measurement of mobility as measured by the $\mathrm{BI}$ is reliable and agreement was generally high for total BI and walking ability. In addition, there was a shorter follow-up period of MRI scans for some patients during hospitalization, mostly due to organizational issues. However, this did not differ between both groups. Finally, due to the relatively small number of immobile patients $(n=22)$, we were unable to reliably examine the individual contribution of risk factors such as disease severity, malnutrition, surgical trauma, inflammation and medication to the actual loss of muscle mass. Thus, this highlights the necessity to establish further studies to address the impact of individual risk factors on the extent of muscle mass loss in the clinical setting.

\section{Conclusion}

We conclude that almost 2 weeks of disease-related immobilization result in a significant loss of thigh muscle mass and muscle strength in older patients with impaired mobility. Concomitantly, there was a significant reduction of subcutaneous adipose tissue in immobile older hospitalized patients whereas no changes were observed in intermuscular fat among these patients. These data should highlight the importance of mobility support in maintaining muscle mass and function in older hospitalized patients.

\section{Abbreviations}

CSA: Cross-sectional area; MRI: Magnetic Resonance Imaging; BI: BarthelIndex; CRP: C-reactive Protein; MNA-SF: Mini Nutritional Assessment Short Form; CCl: Charlson Comorbidity Index 


\section{Acknowledgements}

Not applicable.

\section{Authors' contributions}

The study was designed by RW, NR and MP. Data were obtained by NR. Statistical analysis was performed by MP. MS and DL performed MRI measurement and contributed to the manuscript. MP manually segmented tissue areas. MP, NR, GL, CK, GJ, MS, DL, MJM and RW wrote the manuscript. All authors read and approved the final manuscript.

\section{Funding}

The study was supported by a research grant of the German Society for Nutritional Medicine (DGEM). The sponsor did not have any role in the design of the study, neither in its execution, the collection, analysis or interpretation of data, the decision to submit results nor in writing the report.

\section{Availability of data and materials}

The datasets used and analyzed during the current study available from the corresponding author on reasonable request.

\section{Ethics approval and consent to participate}

The study protocol had been approved by the ethical committee of RuhrUniversity Bochum (17-6048, approved on 08.08.17). Written informed consent was obtained from all participants.

\section{Consent for publication}

Not applicable.

\section{Competing interests}

The authors declare that they have no competing interests.

\section{Author details}

${ }^{1}$ Department of Geriatric Medicine, Marien Hospital Herne, Ruhr-Universität Bochum, Hölkeskampring 40, 44625 Herne, Germany. ${ }^{2}$ Department of Radiology, Marien Hospital Herne, Ruhr-Universität Bochum, Herne, Germany. ${ }^{3}$ Institute of Human Nutrition and Food Science, Christian-Albrechts University, Kiel, Germany.

Received: 4 May 2020 Accepted: 5 November 2020

\section{Published online: 25 November 2020}

\section{References}

1. Goodpaster BH, Park SW, Harris TB, Kritchevsky SB, Nevitt M, Schwartz AV, Simonsick EM, Tylavsky FA, Visser M, Newman AB. The loss of skeletal muscle strength, mass, and quality in older adults: the health, aging and body composition study. J Gerontol A Biol Sci Med Sci. 2006;61(10):1059-64.

2. Buford TW, Anton SD, Judge AR, Marzetti E, Wohlgemuth SE, Carter CS, Leeuwenburgh C, Pahor M, Manini TM. Models of accelerated sarcopenia: critical pieces for solving the puzzle of age-related muscle atrophy. Ageing Res Rev. 2010;9(4):369-83.

3. Rolland Y, Czerwinski S, van Kan GA, Morley JE, Cesari M, Onder G, Woo J, Baumgartner R, Pillard F, Boirie Y, et al. Sarcopenia: its assessment, etiology, pathogenesis, consequences and future perspectives. J Nutr Health Aging. 2008;12(7):433-50

4. Pierik VD, Meskers CGM, Van Ancum JM, Numans ST, Verlaan S, Scheerman $\mathrm{K}$, Kruizinga RC, Maier AB. High risk of malnutrition is associated with low muscle mass in older hospitalized patients - a prospective cohort study. BMC Geriatr. 2017;17(1):118.

5. Robinson SM, Reginster JY, Rizzoli R, Shaw SC, Kanis JA, Bautmans I, BischoffFerrari $\mathrm{H}$, Bruyere $\mathrm{O}$, Cesari M, Dawson-Hughes $\mathrm{B}$, et al. Does nutrition play a role in the prevention and management of sarcopenia? Clin Nutr (Edinburgh, Scotland). 2018;37(4):1121-32.

6. Cruz-Jentoft AJ, Bahat G, Bauer J, Boirie Y, Bruyere O, Cederholm T, Cooper C, Landi F, Rolland Y, Sayer AA, et al. Sarcopenia: revised European consensus on definition and diagnosis. Age Ageing. 2019;48(1):16-31.

7. von Haehling S, Morley JE, Anker SD. An overview of sarcopenia: facts and numbers on prevalence and clinical impact. J Cachexia Sarcopenia Muscle. 2010;1(2):129-33.
8. Pourhassan M, Norman K, Muller MJ, Dziewas R, Wirth R. Impact of sarcopenia on one-year mortality among older hospitalized patients with impaired mobility. J Frailty Aging. 2018;7(1):40-6.

9. Landi F, Calvani R, Tosato M, Martone AM, Bernabei R, Onder G, Marzetti E. Impact of physical function impairment and multimorbidity on mortality among community-living older persons with sarcopaenia: results from the iISIRENTE prospective cohort study. BMJ Open. 2016;6(7):e008281.

10. Fielding RA, Vellas B, Evans WJ, Bhasin S, Morley JE, Newman AB, Abellan van Kan G, Andrieu S, Bauer J, Breuille D, et al. Sarcopenia: an undiagnosed condition in older adults. Current consensus definition: prevalence, etiology, and consequences. International working group on sarcopenia. J Am Med Dir Assoc. 2011;12(4):249-56.

11. Kortebein P, Symons TB, Ferrando A, Paddon-Jones D, Ronsen O, Protas E, Conger S, Lombeida J, Wolfe R, Evans WJ. Functional impact of 10 days of bed rest in healthy older adults. J Gerontol A Biol Sci Med Sci. 2008;63(10): 1076-81.

12. Lang T, Streeper T, Cawthon P, Baldwin K, Taaffe DR, Harris TB. Sarcopenia: etiology, clinical consequences, intervention, and assessment. Osteoporos Int. 2010:21(4):543-59.

13. Vandewoude MF, Alish CJ, Sauer AC, Hegazi RA. Malnutrition-sarcopenia syndrome: is this the future of nutrition screening and assessment for older adults? J Aging Res. 2012;2012:651570.

14. Bell KE, von Allmen MT, Devries MC, Phillips SM. Muscle disuse as a pivotal problem in sarcopenia-related muscle loss and dysfunction. J Frailty Aging. 2016;5(1):33-41.

15. Deutz NE, Pereira SL, Hays NP, Oliver JS, Edens NK, Evans CM, Wolfe RR, et al. Clin Nutr (Edinburgh, Scotland). 2013;32(5):704-12.

16. Dirks ML, Wall BT, Nilwik R, Weerts DH, Verdijk LB, van Loon LJ. Skeletal muscle disuse atrophy is not attenuated by dietary protein supplementation in healthy older men. J Nutr. 2014;144(8):1196-203.

17. Drummond MJ, Dickinson JM, Fry CS, Walker DK, Gundermann DM, Reidy PT, Timmerman KL, Markofski MM, Paddon-Jones D, Rasmussen BB, et al. Bed rest impairs skeletal muscle amino acid transporter expression, mTORC1 signaling, and protein synthesis in response to essential amino acids in older adults. Am J Phys Endocrinol Metab. 2012;302(9):E1113-22.

18. Kortebein P, Ferrando A, Lombeida J, Wolfe R, Evans WJ. Effect of 10 days of bed rest on skeletal muscle in healthy older adults. Jama. 2007;297(16): $1772-4$.

19. Kouw IWK, Groen BBL, Smeets JSJ, Kramer IF, van Kranenburg JMX, Nilwik R, Geurts JAP, Ten Broeke RHM, Poeze M, van Loon LJC, et al. One week of hospitalization following elective hip surgery induces substantial muscle atrophy in older patients. J Am Med Dir Assoc. 2019;20(1):35-42.

20. Cassisa A. Pathophysiology of subcutaneous fat. G Ital Dermatol Venereol. 2013;148(4):315-23.

21. Delmonico MJ, Harris TB, Visser M, Park SW, Conroy MB, Velasquez-Mieyer P, Boudreau R, Manini TM, Nevitt M, Newman AB, et al. Longitudinal study of muscle strength, quality, and adipose tissue infiltration. Am J Clin Nutr. 2009;90(6):1579-85.

22. Goodpaster BH, Carlson CL, Visser M, Kelley DE, Scherzinger A, Harris TB, Stamm E, Newman AB. Attenuation of skeletal muscle and strength in the elderly: The Health ABC Study. J Appl Physiol (Bethesda, Md : 1985). 2001; 90(6):2157-65

23. Visser M, Goodpaster BH, Kritchevsky SB, Newman AB, Nevitt M, Rubin SM Simonsick EM, Harris TB. Muscle mass, muscle strength, and muscle fat infiltration as predictors of incident mobility limitations in well-functioning older persons. J Gerontol A Biol Sci Med Sci. 2005;60(3):324-33.

24. De Carvalho FG, Justice JN, Freitas EC, Kershaw EE, Sparks LM. Adipose tissue quality in aging: how structural and functional aspects of adipose tissue impact skeletal muscle quality. Nutrients. 2019;11(11):2553.

25. Newman AB, Haggerty CL, Goodpaster B, Harris T, Kritchevsky S, Nevitt M, Miles TP, Visser M. Strength and muscle quality in a well-functioning cohort of older adults: the health, aging and body composition study. J Am Geriatr Soc. 2003;51(3):323-30.

26. Newman AB, Kupelian V, Visser M, Simonsick E, Goodpaster B, Nevitt M, Kritchevsky SB, Tylavsky FA, Rubin SM, Harris TB. Sarcopenia: alternative definitions and associations with lower extremity function. J Am Geriatr Soc. 2003;51(11):1602-9.

27. Pourhassan M, Bosy-Westphal A, Schautz B, Braun W, Gluer CC, Muller MJ. Impact of body composition during weight change on resting energy expenditure and homeostasis model assessment index in overweight nonsmoking adults. Am J Clin Nutr. 2014;99(4):779-91. 
28. Pourhassan M, Schautz B, Braun W, Gluer CC, Bosy-Westphal A, Muller MJ. Impact of body-composition methodology on the composition of weight loss and weight gain. Eur J Clin Nutr. 2013;67(5):446-54.

29. Schweitzer L, Geisler C, Pourhassan M, Braun W, Gluer CC, Bosy-Westphal A, Muller MJ. What is the best reference site for a single MRI slice to assess whole-body skeletal muscle and adipose tissue volumes in healthy adults? Am J Clin Nutr. 2015;102(1):58-65.

30. Cotofana S, Hudelmaier M, Wirth W, Himmer M, Ring-Dimitriou S, Sanger AM, Eckstein F. Correlation between single-slice muscle anatomical crosssectional area and muscle volume in thigh extensors, flexors and adductors of perimenopausal women. Eur J Appl Physiol. 2010;110(1):91-7.

31. Yang YX, Chong MS, Lim WS, Tay L, Yew S, Yeo A, Tan CH. Validity of estimating muscle and fat volume from a single MRI section in older adults with sarcopenia and sarcopenic obesity. Clin Radiol. 2017;72(5):427.e429-14.

32. Bean JF, Leveille SG, Kiely DK, Bandinelli S, Guralnik JM, Ferrucci L. A comparison of leg power and leg strength within the InCHIANTI study: which influences mobility more? J Gerontol Ser A, Biol Sci Med Sci. 2003; 58(8):728-33.

33. Pourhassan M, Rommersbach N, Lueg G, Klimek C, Schnatmann M, Liermann D, Janssen G, Wirth R. The impact of malnutrition on acute muscle wasting in frail older hospitalized patients. Nutrients. 2020;12(5): 1387.

34. Mahoney FI, Barthel DW. Functional evaluation: the Barthel index. Maryland State Med J. 1965;14:61-5.

35. Abellan van Kan G, Rolland YM, Morley JE, Vellas B. Frailty: toward a clinical definition. J Am Med Dir Assoc. 2008;9(2):71-2

36. Malmstrom TK, Miller DK, Simonsick EM, Ferrucci L, Morley JE. SARC-F: a symptom score to predict persons with sarcopenia at risk for poor functional outcomes. J Cachexia Sarcopenia Muscle. 2016;7(1):28-36.

37. Charlson ME, Pompei $P$, Ales KL, Mackenzie CR. A new method of classifying prognostic comorbidity in longitudinal studies: development and validation. J Chronic Dis. 1987;40(5):373-83.

38. Kaiser MJ, Bauer JM, Ramsch C, Uter W, Guigoz Y, Cederholm T, Thomas DR, Anthony $\mathrm{P}$, Charlton KE, Maggio $\mathrm{M}$, et al. Validation of the mini nutritional assessment short-form (MNA-SF): a practical tool for identification of nutritional status. J Nutr Health Aging. 2009;13(9):782-8.

39. Bjornsdottir R, Oskarsdottir ES, Thordardottir FR, Ramel A, Thorsdottir I, Gunnarsdottir I. Validation of a plate diagram sheet for estimation of energy and protein intake in hospitalized patients. Clin Nutr (Edinburgh, Scotland). 2013;32(5):746-51.

40. Gandevia SC. Spinal and supraspinal factors in human muscle fatigue. Physiol Rev. 2001;81(4):1725-89.

41. Suetta C, Hvid LG, Justesen L, Christensen U, Neergaard K, Simonsen L, Ortenblad N, Magnusson SP, Kjaer M, Aagaard P. Effects of aging on human skeletal muscle after immobilization and retraining. J Appl Physiol (Bethesda, Md : 1985). 2009;107(4):1172-80.

42. Brown CJ, Friedkin RJ, Inouye SK. Prevalence and outcomes of low mobility in hospitalized older patients. J Am Geriatr Soc. 2004;52(8):1263-70.

43. Zisberg A, Shadmi E, Sinoff G, Gur-Yaish N, Srulovici E, Admi H. Low mobility during hospitalization and functional decline in older adults. J Am Geriatr Soc. 2011;59(2):266-73.

44. Puthucheary ZA, Rawal J, McPhail M, Connolly B, Ratnayake G, Chan P, Hopkinson NS, Phadke R, Dew T, Sidhu PS, et al. Acute skeletal muscle wasting in critical illness. Jama. 2013;310(15):1591-600.

45. de Godoy I, Donahoe M, Calhoun WJ, Mancino J, Rogers RM. Elevated TNFalpha production by peripheral blood monocytes of weight-losing COPD patients. Am J Respir Crit Care Med. 1996;153(2):633-7.

46. Johnson KL. Neuromuscular complications in the intensive care unit: critical illness polyneuromyopathy. AACN Adv Crit Care. 2007;18(2):167-80 quiz 181-162.

47. Yoshiko A, Yamauchi K, Kato T, Ishida K, Koike T, Oshida Y, Akima H. Effects of post-fracture non-weight-bearing immobilization on muscle atrophy, intramuscular and intermuscular adipose tissues in the thigh and calf. Skelet Radiol. 2018;47(11):1541-9.

48. Boettcher M, Machann J, Stefan N, Thamer C, Haring HU, Claussen CD, Fritsche A, Schick F. Intermuscular adipose tissue (IMAT): association with other adipose tissue compartments and insulin sensitivity. J Magn Reson Imaging. 2009;29(6):1340-5.

49. Sepe A, Tchkonia T, Thomou T, Zamboni M, Kirkland JL. Aging and regional differences in fat cell progenitors - a mini-review. Gerontology. 2011;57(1): $66-75$.
50. Zamboni M, Gattazzo S, Rossi AP. Myosteatosis: a relevant, yet poorly explored element of sarcopenia. Eur Geriatr Med. 2019;10(1):5-6.

51. Manini TM, Clark BC, Nalls MA, Goodpaster BH, Ploutz-Snyder LL, Harris TB. Reduced physical activity increases intermuscular adipose tissue in healthy young adults. Am J Clin Nutr. 2007;85(2):377-84.

52. Elder CP, Apple DF, Bickel CS, Meyer RA, Dudley GA. Intramuscular fat and glucose tolerance after spinal cord injury--a cross-sectional study. Spinal Cord. 2004;42(12):711-6.

53. Peterson SJ, Braunschweig CA. Prevalence of sarcopenia and associated outcomes in the clinical setting. NutrClin Pract. 2016;31(1):40-8.

54. Green J, Forster A, Young J. A test-retest reliability study of the Barthel index, the Rivermead mobility index, the Nottingham extended activities of daily living scale and the Frenchay activities index in stroke patients. Disabil Rehabil. 2001;23(15):670-6.

\section{Publisher's Note}

Springer Nature remains neutral with regard to jurisdictional claims in published maps and institutional affiliations.
Ready to submit your research? Choose BMC and benefit from:

- fast, convenient online submission

- thorough peer review by experienced researchers in your field

- rapid publication on acceptance

- support for research data, including large and complex data types

- gold Open Access which fosters wider collaboration and increased citations

- maximum visibility for your research: over $100 \mathrm{M}$ website views per year

At BMC, research is always in progress.

Learn more biomedcentral.com/submissions 